\title{
RESEARCH
}

Open Access

\section{Risk and early predictive factors of anastomotic leakage in laparoscopic low anterior resection for rectal cancer}

\author{
Masahiro Fukada*, Nobuhisa Matsuhashi, Takao Takahashi, Hisashi Imai, Yoshihiro Tanaka, Kazuya Yamaguchi and
} Kazuhiro Yoshida

\begin{abstract}
Background: In recent years, laparoscopic surgery has been widely used for rectal cancer. In laparoscopic rectal surgery, a double-stapling technique (DST) anastomosis using a stapling device is considered a relatively difficult procedure. Postoperative anastomotic leakage (AL) is a major complication related to patients' quality of life and prognosis.

Methods: This study was a retrospective, single-institution study of 101 rectal cancer patients who underwent laparoscopic low anterior resection (LAR) with DST anastomosis (excluding simultaneous resection of other organs and construction of protective diverting stoma) between February 2008 and November 2017 at the Gifu University Graduate School of Medicine. This study aimed to identify risk and early predictive factors of AL.

Results: Among 101 patients, symptomatic AL occurred in 13 patients (12.9\%), of whom 10 were male and 3 were female. Their median BMI was $22.7 \mathrm{~kg} / \mathrm{m}^{2}$ (range, $17.9-26.4 \mathrm{~kg} / \mathrm{m}^{2}$ ).

Among the pre- and intraoperative factors, AL was significantly associated with tumor location (lower rectum), distance from the anal verge $(<6 \mathrm{~cm})$, intraoperative blood loss $(\geq 50 \mathrm{ml})$, and the number of linear staples $(\geq 2)$ in univariate analysis. In multivariate analysis, only intraoperative blood loss ( $\geq 50 \mathrm{ml}$, odds ratio [OR] 4.59; 95\% confidence interval $[\mathrm{Cl}]$ 1.04-19.52; $p=0.045$ ) was identified as an independent risk factor for AL.

Among the postoperative factors, AL was significantly associated with tachycardia-POD1 ( $\geq 100 \mathrm{bpm})$, CRP-POD3 ( $\geq$ $15 \mathrm{mg} / \mathrm{dl}$ ), fever on postoperative day (fever-POD) $3\left(\geq 38^{\circ} \mathrm{C}\right)$, and first defecation day after surgery $(<\mathrm{POD} 3)$ in univariate analysis. In multivariate analysis, fever-POD3 ( $\geq 38^{\circ} \mathrm{C}$, OR 30.97; 95\% Cl 4.68-311.22; $p=0.0003$ ) and first defecation day after surgery ( $<$ POD3, OR 5.82; $95 \% \mathrm{Cl} 1.34-31.30 ; p=0.019)$ were identified as early predictive factors for AL.

Conclusion: In this study, intraoperative blood loss was an indicator of difficulty in a transection and anastomosing procedure, and fever-POD3 and early first defecation day after surgery were independent early predictive factors for AL. Careful surgery using an appropriate technique and standardized procedures with minimal bleeding and careful postoperative management paying attention to fever and defecation may prevent the onset and severity of AL.
\end{abstract}

Keywords: Rectal cancer, Anastomotic leakage, Double-stapling technique, Laparoscopic low anterior resection

\footnotetext{
* Correspondence: flyhighvb@yahoo.co.jp

Department of Surgical Oncology, Graduate School of Medicine, Gifu

University, 1-1 Yanagido, Gifu City, Gifu 501-1194, Japan
}

(c) The Author(s). 2019 Open Access This article is distributed under the terms of the Creative Commons Attribution 4.0 International License (http://creativecommons.org/licenses/by/4.0/), which permits unrestricted use, distribution, and reproduction in any medium, provided you give appropriate credit to the original author(s) and the source, provide a link to the Creative Commons license, and indicate if changes were made. The Creative Commons Public Domain Dedication waiver (http://creativecommons.org/publicdomain/zero/1.0/) applies to the data made available in this article, unless otherwise stated. 


\section{Introduction}

With the development of laparoscopic surgery, laparoscopic rectal surgery has become a widespread intervention for rectal cancer; in fact, according to a report by the Japanese Society for Endoscopic Surgery (JSES), there have been 10,288 cases in 2017 alone. Laparoscopic surgery is now the standard operation instead of open surgery for rectal cancer.

Postoperative anastomotic leakage $(\mathrm{AL})$ is a major complication in laparoscopic rectal surgery that is related to patients' quality of life (QOL) and prognosis, especially morbidity, mortality, functional defects, and oncologic outcomes [1-3]. Despite technical improvements and instrumental developments, rectal transection and double-stapling technique (DST) anastomosis using linear and circular staples are relatively difficult. Hence, the AL rate remains at 6.3-13.7\% [4-9].

In addition, when AL occurs, re-operation and treatment for peritonitis are required. Hence, postoperative hospital stays become longer. In the case of advanced cancer with lymph node metastasis, the introduction of postoperative adjuvant chemotherapy may be delayed, which may lead to an increased recurrence rate and poor prognosis.

The present study had two clinical objectives: (1) identifying risk factors by the evaluation of pre- and intraoperative factors and (2) identifying early predictive factors by the evaluation of postoperative factors. Our aim is to improve patient outcomes by identifying these factors to prevent the occurrence and severity of AL.

\section{Materials and methods Study population}

A total of 154 patients consecutively underwent elective laparoscopic low anterior resection (LAR) with a DST anastomosis at the Department of Surgical Oncology, Gifu University Graduate School of Medicine, between February 2008 and November 2017. Among those patients, 53 were excluded for tumor histopathology other than adenocarcinoma $(n=6)$; conversion to open surgery $(n=2)$; lateral lymph node dissection $(n=2)$; simultaneous resection of other organs $(n=13)$; and construction of protective diverting stoma (DS) $(n=30)$ (Fig. 1). Ultimately, a total of 101 patients with primary rectal cancers were included in this study. We included only symptomatic $\mathrm{AL}$ requiring therapeutic interventions or an operation in the present study. Therefore, DS cases were excluded. No patients had preoperative chemotherapy or chemoradiotherapy. In our department, primary resection is routinely performed before chemotherapy, even for the cases with distant metastases. In addition, preoperative chemotherapy or chemoradiotherapy is selected for difficult cases such as bulky tumors or extramural invasion. Preoperative treatment should be performed in those cases after construction of the colostomy for safer treatment.

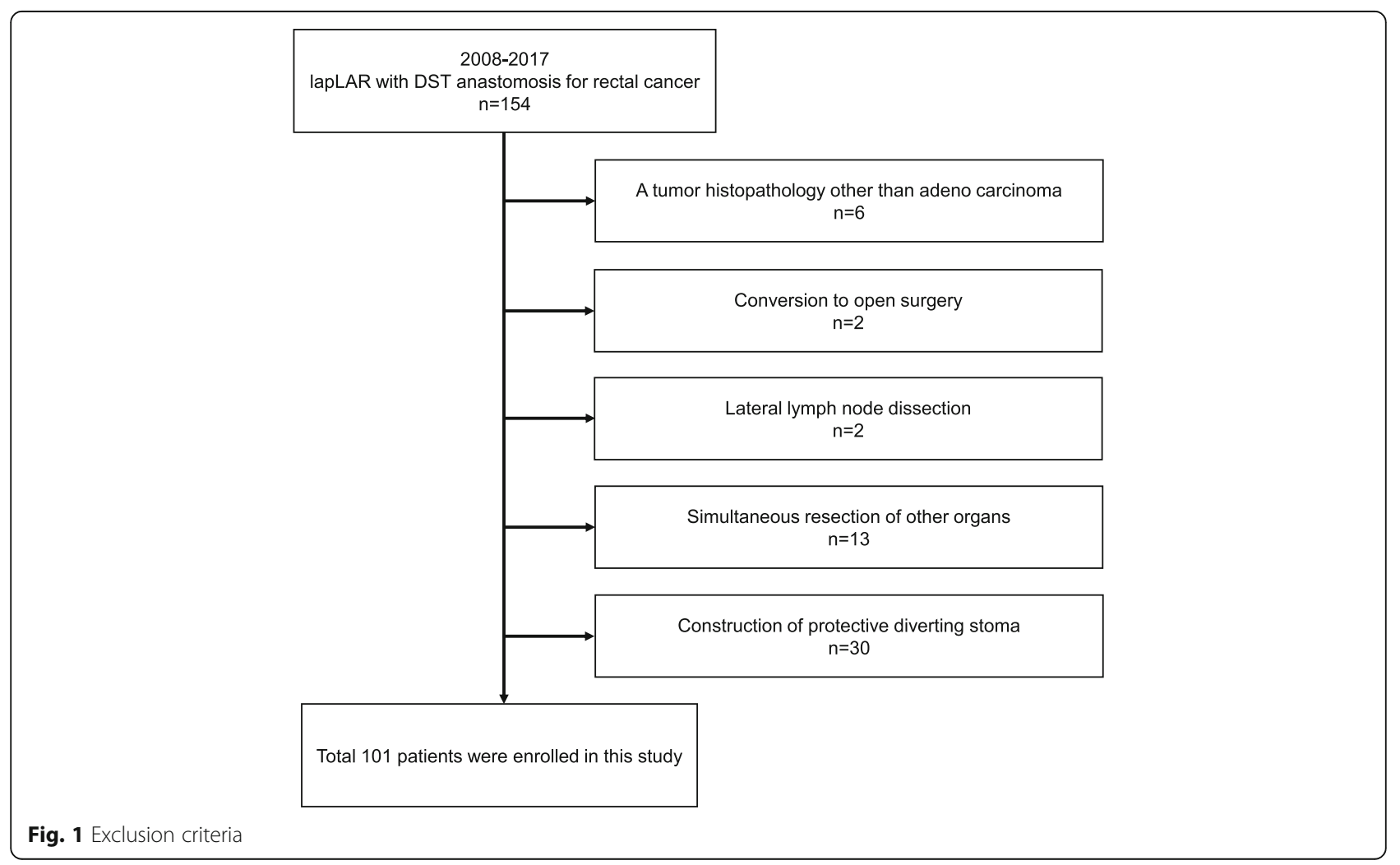


The location of the tumor and distance from the anal verge was determined by computed tomography (CT), colonoscopy (CS), and either CT colonography (CTC) or barium enema (BE) preoperatively and confirmed during surgery. The maximum tumor diameter, clinical tumor depth, and lymph node metastasis were also determined by CT, CS, and CTC or BE preoperatively and confirmed through postoperative histopathological examination findings. Clinically positive lymph node metastasis was defined as nodes with a short-axis diameter of at least 8 $\mathrm{mm}$ by $\mathrm{CT}$. In the present study, postoperative fever was defined as a body temperature $\geq 38^{\circ} \mathrm{C}$ and postoperative tachycardia as a heart rate $\geq 100 \mathrm{bpm}$.

Patient-, tumor-, and surgery-related variables were included in the analysis. The patient-related variables were age, sex, body mass index (BMI), American Society of Anesthesiologists physical status classification (ASA), diabetes mellitus, serum albumin (Alb), and prognostic nutritional index (PNI). The tumor-related variables were tumor location, maximum tumor diameter, distance from the anal verge, circumferential tumor, preoperative stent placement, and clinical and pathological Union for International Cancer Control-TNM classification (8th edition) [10]. The intraoperative surgeryrelated variables were operation time, blood loss, lymph node dissection level (D2 or D3), left colic artery (LCA) preservation, mobilization of the splenic flexure, number of linear staples used for rectal transection, size of the circular staple, placement of the transanal drain, and surgeon qualifications. The postoperative surgery-related variables were white blood cell (WBC) count, C-reactive protein (CRP) levels, fever, tachycardia, watery stools after surgery, and first defecation day after surgery. To resolve clinical questions, they were classified into pre-, intra-, and postoperative factors.

\section{Surgical methods}

All procedures were conducted at our department by an experienced laparoscopic colorectal surgeon qualified by the Endoscopic Surgical Skill Qualification System of the JSES. "Qualified surgeon," one of the surgery-related factors, indicates a case in which a qualified surgeon completed the operation as the main operator. In all other cases, a qualified surgeon supervised as the first assistant.

According to the recommended clinical pathway, all patients received standard bowel preparation by the administration of magnesium citrate and sennoside 2 days before surgery (only mechanical prophylaxis, no antibiotic prophylaxis). In cases where a stent was placed, bowel preparation was slowly performed for 2-3 weeks after placement. Thereafter, a total colonoscopy was performed to confirm that there were no other lesions and that sufficient preparation was done before the surgery was approved and carried out.

We routinely performed high ligation of the inferior mesenteric artery, although preservation of the LCA was considered depending on blood vessel condition. The splenic flexure was mobilized either totally or partially, depending on the bowel length. After mobilization of the descending colon, tumor-specific mesorectal dissection was performed by sharp mesorectal dissection with a nerve-preserving technique. After clamping the distal side of the tumor to wash out the rectum, the rectum was transected using a linear staple (Echelon 60 or Powered Echelon 60, Gold cartridge, Ethicon Endo-Surgery, Cincinnati, OH, USA). After the surgical specimen was removed through the small incision, the anvil head of a circular staple was positioned in the proximal colon. The circular staple (CDH, $25 \mathrm{~mm}$ or $29 \mathrm{~mm}$, Ethicon) was inserted through the rectum, and DST anastomosis was completed intracorporeally. Airtightness was routinely tested by transanal instillation of air. If the leak test was positive, an intracorporeal reinforcement suture with 3-0 vicryl was placed at the weak point. The placement of a pelvic drain was routinely performed, and placement of the transanal drain (pleated drain-soft type, $10 \mathrm{~mm}$, Sumitomo Bakelite Company Limited, Shinagawa, Tokyo, Japan) was performed depending on the location of the tumor and the height of the anastomosis from the anal verge. The transanal drain was removed 4-5 days after surgery.

\section{Definition of anastomotic leakage}

$\mathrm{AL}$ was investigated in the presence of clinical leakage signs such as the discharge of pus or feces from the pelvic drain and evidence of peritonitis, including abdominal pain, tenderness, fever, tachycardia, or severe inflammation in blood tests. If leakage was suspected, CT was performed to check for AL. Diagnosis required positive findings on CT, such as an abscess and fluid collection or air bubbles surrounding the anastomosis site. Asymptomatic anastomosis leakage was not considered as contrast enemas were not routinely performed in our department.

\section{Statistical analysis}

Continuous variables were expressed as median values, while categorical and ordinal variables were expressed as frequencies (percentages). For comparisons of variables between the non-AL and AL groups, Fisher's exact test was used for categorical variables, and Wilcoxon rank sum tests were used for continuous and ordinal variables. To test the independence of risk and early predictive factors for AL, significant variables in univariate analyses were included in a final model of logistic 
regression. All statistical analyses were performed using JMP software (SAS Institute Inc., Cary, NC, USA).

\section{Results}

\section{Patient and tumor characteristics}

In total, 101 consecutive patients underwent laparoscopic LAR with DST anastomosis, 53 (52.5\%) were male and $48(47.5 \%)$ were female. The median age was 64 years (range, 18-83 years) and their median BMI was $22 \mathrm{~kg} / \mathrm{m}^{2}$ (range, $15.4-29.7 \mathrm{~kg} / \mathrm{m}^{2}$ ). Twenty-five patients (24.7\%) had rectosigmoid (RS) cancer, 63 (62.4\%) had upper rectal $(\mathrm{Ra})$ cancer, and the remaining 13 (12.9\%) had lower rectal $(\mathrm{Rb})$ cancer.

\section{Anastomotic leakage}

Among the patients, symptomatic AL occurred in 13 patients (12.9\%), of whom 10 were male and 3 were female. Their median BMI was $22.7 \mathrm{~kg} / \mathrm{m}^{2}$ (range, $17.9-26.4 \mathrm{~kg} /$ $\left.\mathrm{m}^{2}\right)$. The AL rate was $12.0 \%(3 / 25)$ in patients with $\mathrm{RS}$ cancer, 7.9\% (5/63) in Ra cancer, and 38.5\% (5/13) in Rb cancer. AL requiring re-operation (stoma construction) occurred in 5 cases (38.5\%), while there were 8 cases (61.5\%) of AL that did not require re-operation and were treated by irrigation and drainage through the pelvic drain. Antibiotics were administered in all AL cases until the inflammatory response was reduced or there were no signs of inflammation. The median time at which AL was confirmed was POD 4 (range, 1-10 days), and the median time until hospital discharge was 43 days postsurgery (range, 24-242 days). There were no deaths related to AL in this study.

\section{Patient-related factors for AL}

Patient-related factors are summarized in Table 1. No significant differences were found, which was consistent even when converting continuous and ordinal variables into categorical variables [age ( $\geq 75$ years $/<75$ years), BMI $\left(\geq 25 \mathrm{~kg} / \mathrm{m}^{2} /<25 \mathrm{~kg} / \mathrm{m}^{2}\right)$, ASA $(\geq 2 /<2)$, Alb $(\geq 3.5$ $\mathrm{g} / \mathrm{dl} /<3.5 \mathrm{~g} / \mathrm{dl})$, and PNI $(\geq 45 /<45)]$. In this study, we set a BMI cutoff value of $\geq 25 \mathrm{~kg} / \mathrm{m}^{2}$ based on the definition of obesity in the Japanese Society for the Study of Obesity (JASSO) instead of $30 \mathrm{~kg} / \mathrm{m}^{2}$ as per the International Federation of Surgery for Obesity and Metabolic disorder (IFSO).

\section{Tumor-related factors for AL}

Clinical and pathological tumor-related factors are summarized in Table 2. AL was significantly associated with tumor location $(p=0.031)$ and distance from the anal verge $(p=0.040)$. There were significant differences in tumor location (Rb, $p=0.0046)$ and distance from the anal verge $(<6 \mathrm{~cm}, p=0.0090)$ after converting continuous and ordinal variables into categorical variables [tumor location ( $\mathrm{Rb} /$ not $\mathrm{Rb})$, tumor diameter $(\geq 40 \mathrm{~mm} /<40 \mathrm{~mm})$, distance from the anal verge $(\geq 6 \mathrm{~cm} /<6 \mathrm{~cm})$, cT $(\geq 3 /<3)$, $\mathrm{cN}$ (positive/negative), cStage $(\geq \mathrm{III} /<\mathrm{III}), \mathrm{pT}(\geq 3 /<3), \mathrm{pN}$ (positive/negative), and fStage $(\geq \mathrm{III} /<\mathrm{III})]$.

\section{Surgery-related factors for AL}

Surgery-related factors are summarized in Table 3. AL was significantly associated with the number of linear staples $(p=0.046)$, tachycardia-POD1 $(p=0.023)$, CRPPOD3 $(p=0.036)$, fever-POD3 $(p<0.0001)$, and first defecation day after surgery $(p=0.022)$. There were

Table 1 Patients related factors for $\mathrm{AL}$

\begin{tabular}{|c|c|c|c|}
\hline Patient related factor & Leakage $(-), n=88$ & Leakage $(+), n=13$ & $p$ value \\
\hline Age (years), median [range] & 64.5 [18 83] & 60 [36 79] & 0.39 \\
\hline \multicolumn{4}{|l|}{ Sex, $n=$ No. $(\%)$} \\
\hline Male & $43(48.9)$ & $10(76.9)$ & \multirow[t]{2}{*}{0.077} \\
\hline Female & $45(51.1)$ & $3(23.1)$ & \\
\hline Body mass index, median [range] & $21.75[15.4 \sim 29.7]$ & $22.7[17.9 \sim 26.4]$ & 0.24 \\
\hline \multicolumn{4}{|l|}{ ASA, $n=$ No. $(\%)$} \\
\hline 1 & $29(33.0)$ & $5(38.5)$ & \multirow[t]{3}{*}{0.82} \\
\hline 2 & $58(65.9)$ & $8(61.5)$ & \\
\hline 3 & $1(1.1)$ & $0(0)$ & \\
\hline \multicolumn{4}{|l|}{ Diabetes mellitus, $n=$ No. (\%) } \\
\hline Yes & $16(18.2)$ & $5(38.5)$ & \multirow[t]{2}{*}{0.14} \\
\hline No & $72(81.8)$ & $8(61.5)$ & \\
\hline Albumin (g/dl), median [range] & $4.3[2.7 \sim 4.9]$ & $4.4[3.2 \sim 4.9]$ & 0.79 \\
\hline PNI, median [range] & $52.1[30.6 \sim 63.9]$ & $53.4[40.6 \sim 65.9]$ & 0.50 \\
\hline
\end{tabular}

$A L$ anastomotic leakage, $A S A$ American Society of Anesthesiologists physical status classification, $P N /$ prognostic nutritional index $=10 \times \mathrm{Alb}(\mathrm{g} / \mathrm{dl})+0.005 \times$ total lymphocyte count $\left(\mathrm{mm}^{3}\right)$

${ }^{+} p<0.05$ 
Table 2 Tumor related factors for AL

\begin{tabular}{|c|c|c|c|}
\hline Tumor related factors & Leakage $(-), n=88$ & Leakage $(+), n=13$ & $p$ value \\
\hline \multicolumn{4}{|l|}{ Clinical } \\
\hline \multicolumn{4}{|l|}{ Tumor location, $n=$ No. (\%) } \\
\hline Rs & $22(25.0)$ & $3(23.0)$ & \multirow[t]{3}{*}{$0.031 t$} \\
\hline Ra & $58(65.9)$ & $5(38.5)$ & \\
\hline $\mathrm{Rb}$ & $8(9.1)$ & $5(38.5)$ & \\
\hline Tumor diameter (mm), median [range] & $35[5 \sim 112]$ & 42 [10 100] & 0.36 \\
\hline Anal verge $(\mathrm{cm})$, median [range] & $13[5 \sim 30]$ & $10[5 \sim 20]$ & $0.040 t$ \\
\hline \multicolumn{4}{|l|}{ Circumferential tumor, $n=$ No. $(\%)$} \\
\hline Yes & $19(21.8)$ & $4(30.8)$ & \multirow[t]{2}{*}{0.49} \\
\hline No & $68(78.2)$ & $9(69.2)$ & \\
\hline \multicolumn{4}{|l|}{ Stent placement, $n=$ No. $(\%)$} \\
\hline Yes & $5(5.7)$ & $2(15.4)$ & \multirow[t]{2}{*}{0.22} \\
\hline No & $83(94.3)$ & $11(84.6)$ & \\
\hline \multicolumn{4}{|l|}{$\mathrm{cT}, n=$ No. $(\%)$} \\
\hline 1 & $18(20.4)$ & $3(23.1)$ & \multirow[t]{4}{*}{0.94} \\
\hline 2 & $18(20.4)$ & $2(15.4)$ & \\
\hline 3 & $35(39.8)$ & $6(46.1)$ & \\
\hline 4 & $17(19.4)$ & $2(15.4)$ & \\
\hline \multicolumn{4}{|l|}{$\mathrm{cN}, n=\mathrm{No} .(\%)$} \\
\hline 0 & $60(68.2)$ & $7(54.0)$ & \multirow[t]{3}{*}{0.49} \\
\hline 1 & $18(20.5)$ & $3(23.0)$ & \\
\hline 2 & $10(11.3)$ & $3(23.0)$ & \\
\hline \multicolumn{4}{|l|}{ cStage, $n=$ No. (\%) } \\
\hline I & $36(40.9)$ & $5(38.5)$ & \multirow[t]{4}{*}{0.83} \\
\hline$\|$ & $21(23.9)$ & $2(15.4)$ & \\
\hline III & $23(26.1)$ & $4(30.7)$ & \\
\hline IV & $8(9.1)$ & $2(15.4)$ & \\
\hline \multicolumn{4}{|l|}{ Pathological } \\
\hline \multicolumn{4}{|l|}{$\mathrm{pT}, n=$ No. $(\%)$} \\
\hline 1 & $24(27.3)$ & $3(23.1)$ & \multirow[t]{4}{*}{0.74} \\
\hline 2 & 19 (21.6) & $4(30.8)$ & \\
\hline 3 & $30(34.1)$ & $5(38.4)$ & \\
\hline 4 & $15(17.0)$ & $1(7.7)$ & \\
\hline \multicolumn{4}{|l|}{$\mathrm{pN}, n=\mathrm{No} .(\%)$} \\
\hline 0 & $57(64.8)$ & $6(46.1)$ & \multirow[t]{3}{*}{0.098} \\
\hline 1 & $20(22.7)$ & $2(15.4)$ & \\
\hline 2 & $11(12.5)$ & $5(38.5)$ & \\
\hline \multicolumn{4}{|l|}{ fStage, $n=$ No. (\%) } \\
\hline । & $37(42.0)$ & $5(41.7)$ & \multirow[t]{4}{*}{0.15} \\
\hline$\|$ & $17(19.3)$ & $0(0.0)$ & \\
\hline III & $26(29.6)$ & $5(41.7)$ & \\
\hline IV & $8(9.1)$ & $2(16.6)$ & \\
\hline
\end{tabular}


Table 3 Surgery related factors for AL

\begin{tabular}{|c|c|c|c|}
\hline Surgery related factors & Leakage $(-), n=88$ & Leakage $(+), n=13$ & $p$ value \\
\hline \multicolumn{4}{|l|}{ Intraoperative } \\
\hline Operation time (min), median [range] & 233 [151 438] & $263[157 \sim 376]$ & 0.32 \\
\hline Blood loss (ml), median [range] & 10 [0 180] & 15 [0 1115] & 0.15 \\
\hline \multicolumn{4}{|l|}{ Lymph node dissection, $n=$ No. (\%) } \\
\hline D2 & $18(20.5)$ & $1(7.7)$ & \multirow[t]{2}{*}{0.45} \\
\hline D3 & $70(79.5)$ & $12(92.3)$ & \\
\hline \multicolumn{4}{|l|}{ LCA preserving, $n=$ No. (\%) } \\
\hline Yes & $36(40.9)$ & $4(30.8)$ & \multirow[t]{2}{*}{0.56} \\
\hline No & $52(59.1)$ & $9(69.2)$ & \\
\hline \multicolumn{4}{|l|}{ Mobilization of splenic flexure, $n=$ No. (\%) } \\
\hline Yes & $3(3.4)$ & $1(7.7)$ & \multirow[t]{2}{*}{0.43} \\
\hline No & 85 (96.6) & $12(92.3)$ & \\
\hline \multicolumn{4}{|l|}{ Number of linear staple, $n=$ No. (\%) } \\
\hline 1 & $66(75.0)$ & $6(46.1)$ & \multirow[t]{2}{*}{$0.046^{\dagger}$} \\
\hline 2 & $22(25.0)$ & $7(53.9)$ & \\
\hline \multicolumn{4}{|l|}{ Size of circular staple $(\mathrm{mm}), n=$ No. $(\%)$} \\
\hline 25 & $7(8.1)$ & $1(7.7)$ & \multirow[t]{2}{*}{1.00} \\
\hline 29 & $80(91.9)$ & $12(92.3)$ & \\
\hline \multicolumn{4}{|l|}{ Trans anal drain, $n=$ No. (\%) } \\
\hline Yes & $51(58.0)$ & $8(61.5)$ & \multirow[t]{2}{*}{1.00} \\
\hline No & $37(42.0)$ & $5(38.5)$ & \\
\hline \multicolumn{4}{|l|}{ Qualified surgeon, $n=$ No. (\%) } \\
\hline Yes & $65(73.9)$ & $11(84.6)$ & \multirow[t]{2}{*}{0.51} \\
\hline No & $23(26.1)$ & $2(15.4)$ & \\
\hline \multicolumn{4}{|l|}{ Postoperative } \\
\hline \multicolumn{4}{|l|}{ WBC $(/ \mu l)$ median [range] } \\
\hline POD1 & $8280[2790 \sim 13,510]$ & $8340[5640 \sim 12,440]$ & 0.069 \\
\hline POD3 & $6975[3220 \sim 15,450]$ & $8100[3390 \sim 17,570]$ & 0.15 \\
\hline \multicolumn{4}{|l|}{ CRP (mg/dl) median [range] } \\
\hline POD1 & $4.95[1.61 \sim 12.7]$ & $4.43[2.35 \sim 14.7]$ & 0.75 \\
\hline POD3 & $6.86[0.37 \sim 23.4]$ & $8.77[1.24 \sim 34.6]$ & $0.036^{\dagger}$ \\
\hline \multicolumn{4}{|l|}{ Fever $\left(\geqq 38^{\circ} \mathrm{C}\right), n=$ No. $(\%)$} \\
\hline POD1 & $40(45.5)$ & $9(69.2)$ & 0.14 \\
\hline POD3 & $5(5.7)$ & $7(53.8)$ & $<0.0001^{\dagger}$ \\
\hline \multicolumn{4}{|l|}{ Tachycardia ( $\geqq 100$ bpm), $n=$ No. (\%) } \\
\hline POD1 & $6(6.8)$ & $4(30.8)$ & $0.023^{t}$ \\
\hline POD3 & $7(8.0)$ & $1(8.0)$ & 1.00 \\
\hline \multicolumn{4}{|l|}{ Watery stool, $n=$ No. $(\%)$} \\
\hline Yes & 34 [39.0] & $6[50.0]$ & \multirow[t]{2}{*}{0.54} \\
\hline No & $53[61.0]$ & $6[50.0]$ & \\
\hline First defecation day (POD), median [range] & 4 [1 13] & $2[0 \sim 7]$ & $0.022^{\dagger}$ \\
\hline
\end{tabular}

$A L$ anastomotic leakage, $L C A$ left colic artery, WBC white blood cell, $C R P$ C-reactive protein, $P O D$ postoperative day ${ }^{+} p<0.05$ 
significant differences in intraoperative blood loss $(\geq 50$ $\mathrm{ml}, p=0.012)$, CRP-POD $3(\geq 15 \mathrm{mg} / \mathrm{dl}, p=0.046)$, and first defecation day (<POD3, $p=0.0059)$ after converting continuous and ordinal variables into categorical variables [operation time $(\geq 240 \mathrm{~min} /<240 \mathrm{~min})$, intraoperative blood loss $(\geq 50 \mathrm{ml} /<50 \mathrm{ml})$, WBC-POD1 ( $\geq 10,000 /$ $\mu \mathrm{l} /<10,000 / \mu \mathrm{l})$, CRP-POD1 $(\geq 5 \mathrm{mg} / \mathrm{dl} /<5 \mathrm{mg} / \mathrm{dl})$, WBCPOD3 $(\geq 10,000 / \mu \mathrm{l} /<10,000 / \mu \mathrm{l})$, CRP-POD3 $(\geq 15 \mathrm{mg} /$ $\mathrm{dl} /<15 \mathrm{mg} / \mathrm{dl})$, and first defecation day $(\geq \mathrm{POD} 3 /<$ POD3)].

\section{Pre-, intra-, and postoperative factors}

To resolve clinical questions, we classified patient-, tumor-, and surgery-related categorical factors, which were significantly different in univariate analysis, into pre-, intra-, and postoperative factors (Fig. 2).

Among the pre- and intraoperative factors, AL was significantly associated with the following four factors in univariate analysis: tumor location $(\mathrm{Rb})$, distance from the anal verge $(<6 \mathrm{~cm})$, intraoperative blood loss $(\geq 50 \mathrm{ml})$, and the number of linear staple $(\geq 2)$. In multivariate analysis, distance from the anal verge $(<6 \mathrm{~cm})$ was excluded to avoid confounding with tumor location $(\mathrm{Rb})$; only intraoperative blood loss $(\geq 50 \mathrm{ml})$ maintained a significant correlation with AL (Table 4; odds ratio (OR) 4.59; 95\% confidence interval (CI) 1.04-19.52; $p=0.045$ ).

Among the postoperative factors, AL was significantly associated with the following four factors in univariate analysis: tachycardia-POD1 ( $\geq 100 \mathrm{bpm})$, CRP-POD3 ( $\geq$ $15 \mathrm{mg} / \mathrm{dl})$, fever-POD3 $\left(\geq 38^{\circ} \mathrm{C}\right)$, and first defecation day after surgery $(<$ POD3). In multivariate analysis, feverPOD3 $\left(\geq 38^{\circ} \mathrm{C}\right)$ and first defecation day after surgery $(<$ POD3) remained significantly correlated with AL (Table 5; OR 30.97; 95\% CI 4.68-311.22; $p=0.0003$ and OR 5.82; CI 1.34-31.30; $p=0.019$, respectively).

\section{Discussion}

$\mathrm{AL}$ is a major complication of laparoscopic rectal surgery. It is associated with postoperative morbidity, mortality, functional defects, and oncologic outcomes [1-3]. Several risk factors have been reported for AL after open LAR [11-15]. Recently, some studies have also examined risk factors for AL after laparoscopic LAR [4, 16-26]. The devices and techniques used for laparoscopic LAR are different from open LAR, suggesting that the risk factors for AL may also differ between laparoscopic and open LAR. According to their studies, anastomotic level, number of linear staples, sex, BMI, smoking, alcohol intake, previous abdominal surgery, preoperative CRT, tumor location, stage, operation time, blood loss, transfusion, and pre-compression before firing have been reported to be risk factors for AL after laparoscopic LAR. In the present study, analysis of preoperative and intraoperative factors suggested that intraoperative blood loss, distance from the anal verge, and number of linear staples may be candidates for risk factors.

Firstly, in some studies, intraoperative blood loss has been reported to be an independent risk factor for AL $[21-23,25,26]$. In the present study, there was no

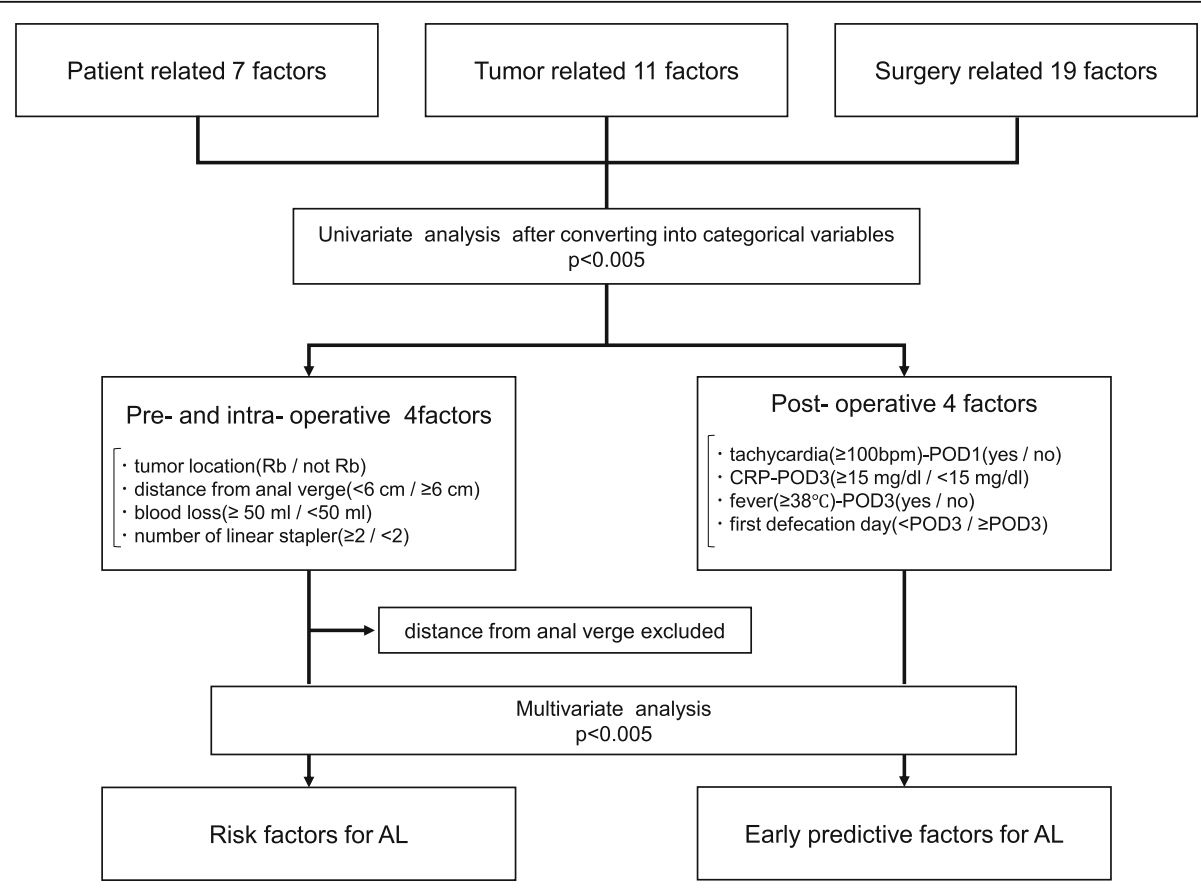

Fig. 2 Analysis flow chart for identifying risk and early predictive factors for anastomotic leakage 
Table 4 Multivariate analysis of pre- and intraoperative factors for $\mathrm{AL}$

\begin{tabular}{llll}
\hline Pre-and intraoperative factors & Odds ratio & $95 \% \mathrm{Cl}$ & $p$ value \\
\hline Tumor location $(\mathrm{Rb} / \mathrm{not} \mathrm{Rb})$ & 2.69 & {$[0.54 \sim 11.68]$} & 0.21 \\
Blood loss $(\geq 50 \mathrm{ml} /<50 \mathrm{ml})$ & 4.59 & {$[1.04 \sim 19.52]$} & $0.045^{\dagger}$ \\
Number of linear staple $(\geq 2 /<2)$ & 2.34 & {$[0.63 \sim 8.61]$} & 0.20 \\
\hline $\begin{array}{l}\text { AL anastomotic leakage } \\
{ }^{\mathbf{p}} p<0.05\end{array}$ & & &
\end{tabular}

significant difference in blood loss as a continuous variable, but a significant difference was observed only when $50 \mathrm{ml}$ was used as a cutoff value. This indicates that AL does not directly manifest due to bleeding, and intraoperative blood loss is likely to be a surrogate for the difficulty of the surgery. The results of this study suggest that intraoperative blood loss of more than $50 \mathrm{ml}$ may be one of the objective indicators of a challenging transection and anastomosing procedure. Therefore, performing well-coordinated laparoscopic surgery using standardized procedures could help to reduce the intraoperative blood loss and to create a proper anastomosis.

Secondly, several studies have reported that tumor location and distance from the anal verge are risk factors for laparoscopic LAR [17-21, 24]. Choi et al. [19] reported that the AL rate was 10 times higher $(20.6 \%$ vs. $2.3 \%)$ when the anastomotic region was located within $5 \mathrm{~cm}$ of the anal verge in a series of 156 patients undergoing laparoscopic LAR without DS. It is hypothesized that tumor location and distance from the anal verge can reflect technical difficulties and affect anastomotic tension and blood supply. In the present study, there were no statistically significant differences between these factors in multivariate analysis; however, we considered that they are very likely to be risk factors for AL. In our department, DS construction has been performed routinely in cases of $\mathrm{Rb}$ cancer requiring transection just above the anal canal $(<5 \mathrm{~cm}$ from the anal verge).

Thirdly, some previous studies reported that the number of linear staples used for rectal transection was a risk factor for AL $[4,17-20,24]$. There is a concern that an increased number of staple firings may lead to small defects between staple lines and cause AL. Furthermore Kim et al. [17] found that more than two staple firings was associated with $\mathrm{AL}$, and the number of linear staples was significantly higher in males, patients with a tumor closer to the rectal verge, and in those with longer operation times. Therefore, the number of linear staples seems to be both a direct and indirect risk factor for AL. Although there was no statistical significance in multivariate analysis, laparoscopic surgeons need to refine their technique to transect the rectum using one linear staple when possible.

Although in univariate analysis, sex (male) showed a significant tendency $(p=0.077)$, no other factors showed significant differences. The nutritional index in this test was analyzed using not only Alb but also PNI. PNI is calculated by Alb and total lymphocyte count, and Onodera et al. [26] reported that resection and anastomosis of the gastrointestinal tract can be safely practiced when the index is $>45$. The same procedure may be dangerous when the PNI score is between 40 and 45 , whereas this kind of operation may be contraindicated when it is below 40. In this study population, the proportion of cases with PNI less than 40 was extremely small $(1 / 101$; $1 \%)$; therefore, we set 45 as the cutoff value. Hence, no significant difference was observed. Nonetheless, a larger-scale study is needed in the future to confirm these results.

For postoperative factors, fever on POD3 and early first defecation after surgery were early predictive factors for AL. Once AL occurs, discharge may take time regardless of treatment. The median time until hospital discharge was 43 (range, 24-242 days) and 11 days post-surgery (range, 7-29 days) for the AL and non-AL groups, respectively. There was no significant difference in the time from the primary operation to hospital discharge between the AL group requiring re-operation and not requiring re-operation [median POD55 (range, 24-242 days) vs. POD42.5 (range, 24-51 days), $p=0.51$ ). According to the analysis of postoperative factors, most AL occurs within POD3 and become a diagnosable symptomatic state after POD4. The time required from the occurrence of $\mathrm{AL}$ to the diagnosis may lead to the development of peritonitis, and thus, normalization of abdominal inflammation may take a long time. Therefore, in

Table 5 Multivariate analysis of postoperative factors for AL

\begin{tabular}{llll}
\hline Postoperative factors & Odds ratio & $95 \% \mathrm{Cl}$ & $p$ value \\
\hline Tachycardia $(\geq 100 \mathrm{bpm})$-POD1 (yes/no) & 4.84 & {$[0.58 \sim 34.59]$} & 0.14 \\
CRP-POD3 ( $\geq 15 \mathrm{mg} / \mathrm{dl} /<15 \mathrm{mg} / \mathrm{dl})$ & 0.28 & {$[0.002 \sim 2.51]$} & 0.27 \\
Fever $\left(\geq 38^{\circ} \mathrm{C}\right.$ )-POD3 (yes/no) & 30.97 & {$[4.68 \sim 311.22]$} & $0.0003^{\dagger}$ \\
First defecation day (<POD3/ $\geq$ POD3) & 5.82 & {$[1.34 \sim 31.30]$} & $0.019^{\dagger}$ \\
\hline
\end{tabular}

$A L$ anastomotic leakage, $C R P$ C-reactive protein, $P O D$ postoperative day 
cases of fever on POD3 and early first defecation after surgery, the onset and diagnosis of AL should be monitored by fasting management and image inspection to prevent peritonitis.

In addition, it has been reported that early first defecation after surgery is a risk factor for AL [27]. Instrumental DST anastomosis within POD7 is insufficient for completion of epithelialization. Therefore, early endoluminal pressure of the first defecation is considered to be a risk factor of AL. Some studies reported that the placement of a transanal drain could prevent AL by reducing endoluminal pressure around the anastomotic site [28-32]. There are slight differences in each subject, such as the material, diameter, length of insertion, and duration of the transanal drain. A standardized procedure for placement of the transanal drain should be validated, and further investigation is required to elucidate its usefulness. With regard to reducing the endoluminal pressure around the anastomotic site, the concept of DS is similar; however, construction of DS increases patients' discomfort and requires further surgery for stoma closure. Therefore, if the efficacy of the prevention of AL is approximately equal for both procedures, a transanal drain is superior to DS. Although there was no statistically significant difference in this study, we predict that the replacement of a transanal drain would be useful to reduce the AL rate.

Some limitations of this study have to be addressed. First, the major limitations of our study are the singleinstitution, retrospective design and small number of patients investigated. In fact, the AL rate in this study was slightly higher in percentage (13\%). This is probably because the present study included the cases in the introduction phase of laparoscopic LAR during standardization of procedures. Furthermore, since advanced cases were not indicated for laparoscopic surgery during the introduction period, it is necessary to consider the possibility of selection bias in factors such as tumor size and TNM classification. Second, DS cases were excluded from the present study because we included only symptomatic AL. This may have also contributed to the high AL rate in this study. Moreover, a lot of DS cases have Rb lesions, which may cause selection bias. Third, preoperative chemotherapy or chemoradiotherapy cases were also excluded from this study because of our treatment policy. Among the cases of preoperative treatment, some highly advanced and difficult cases were included, which may have caused a bias in our results. These limitations should be considered when evaluating the results of the present study. It is necessary to carry out a prospective study with multiple institutions that have a unified definition of AL and standardized procedures.

\section{Conclusion}

In conclusion, we demonstrated that in patients with $\mathrm{AL}$ after laparoscopic LAR with DST anastomosis, intraoperative blood loss was an indicator of difficulty in a transection and anastomosing procedure, and fever-POD3 $\left(\geq 38^{\circ} \mathrm{C}\right)$ and early first defecation day after surgery $(<$ POD3) were independent early predictive factors.

Therefore, careful surgery using an appropriate technique and standardized procedures with minimal bleeding and careful postoperative management paying attention to fever and defecation may prevent the onset and severity of AL.

However, because of the retrospective nature of this study, the limited number of patients, and the multifactorial nature of $\mathrm{AL}$, it is difficult to draw robust conclusions. Further studies that are multi-institutional, randomized, and controlled are required to identify risk and early predictive factors for AL.

\begin{abstract}
Abbreviations
AL: Anastomosis leakage; Alb: Albumin; BMl: Body mass index; Cl: Confidence interval; CRP: C-reactive protein; DS: Diverting stoma; DST: Double-stapling technique; LAR: Low anterior resection; OR: Odds ratio; POD: Postoperative day; Ra: Upper rectal; Rb: Lower rectal; Rs: Rectosigmoid; WBC: White blood cells
\end{abstract}

\section{Acknowledgements}

The authors thank the medical staff of the Department of Surgical Oncology at Gifu University Hospital for their participation in this study. We could not have completed this study without their diligence and support. We would like to thank Editage (www.editage.jp) for English language editing.

\section{Authors' contributions}

MF conceived the study concept and planned the design as the principal investigator. MF interpreted the results and wrote the manuscript draft. NM, $\Pi$, and $K Y$ revised the manuscript draft by adding intellectual insights and provided critical advice. MF, NM, $T$ T, HI, YT, $K Y$, and $K Y$ obtained the data and provided their critical comments to improve the manuscript and gave final approval for submission.

\section{Funding}

None declared

\section{Availability of data and materials}

The datasets used during this study are available from the corresponding author on reasonable request.

\section{Ethics approval and consent to participate}

The present study was conducted in accordance with the World Medical Association Declaration of Helsinki and was approved by the Ethics Committee of Gifu University (approval number '2018-192'). As this study was a retrospective study and did not include any potentially identifiable patient data, informed consent was not obtained from the enrolled patients. The institutional review board gave the ethics approval for this retrospective study.

\section{Consent for publication}

Not applicable.

Competing interests

The authors declare that they have no competing interests. 
Received: 22 July 2019 Accepted: 30 September 2019

Published online: 02 November 2019

\section{References}

1. Walker KG, Bell SW, Rickard MJ, Mehanna D, Dent OF, Chapuis PH, et al. Anastomotic leakage is predictive of diminished survival after potentially curative resection for colorectal cancer. Ann Surg. 2004;240:255-9.

2. Bell SW, Walker KG, Rickard MJ, Sinclair G, Dent OF, Chapuis PH, et al. Anastomotic leakage after curative anterior resection results in a higher prevalence of local recurrence. Br J Surg. 2003;90:1261-6.

3. Hallböök O, Sjödahl R. Anastomotic leakage and functional outcome after anterior resection of the rectum. Br J Surg. 1996;83:60-2.

4. Park JS, Choi GS, Kim SH, Kim HR, Kim NK, Lee KY, et al. Multicenter analysis of risk factors for anastomotic leakage after laparoscopic rectal cancer excision: the Korean laparoscopic colorectal surgery study group. Ann Surg. 2013;257:665-71.

5. Kang CY, Halabi WJ, Chaudhry OO, Nguyen V, Pigazzi A, Carmichael JC, et al. Risk factors for anastomotic leakage after anterior resection for rectal cancer. JAMA Surg. 2013;148:65-71.

6. den Dulk M, Marijnen CA, Collette L, Putter H, Påhlman L, Folkesson J, et al. Multicentre analysis of oncological and survival outcomes following anastomotic leakage after rectal cancer surgery. Br J Surg. 2009;96:1066-75.

7. Peeters KC, Tollenaar RA, Marijnen CA, Klein Kranenbarg E, Steup WH, Wiggers T, et al. Risk factors for anastomotic failure after total mesorectal excision of rectal cancer. Br J Surg. 2005;92:211-6.

8. Paun BC, Cassie S, MacLean AR, Dixon E, Buie WD. Postoperative complications following surgery for rectal cancer. Ann Surg. 2010;251: 807-18.

9. Snijders HS, Wouters MW, van Leersum NJ, Kolfschoten NE, Henneman D, Vries AC, et al. Metaanalysis of the risk for anastomotic leakage, the postoperative mortality caused by leakage in relation to the overall postoperative mortality. Eur J Surg Oncol. 2012;38:1013-9.

10. Brierley JD, Gospodarowicz MK, Wittekind C. International Union Against Cancer. TNM Classification of Malignant Tumors. 8th edition. Chichester: Wiley, Blackwell; 2017.

11. Rullier E, Laurent C, Garrelon JL, Michel P, Saric J, Parneix M. Risk factors for anastomotic leakage after resection of rectal cancer. $\mathrm{Br}$ J Surg. 1998;85:355-8

12. Yeh CY, Changchien CR, Wang JY, Chen JS, Chen HH, Chiang JM, Tang R. Pelvic drainage and other risk factors for leakage after elective anterior resection in rectal cancer patients: a prospective study of 978 patients. Ann Surg. 2005;241:9-13

13. Jung SH, Yu CS, Choi PW, Kim DD, Park IJ, Kim HC, Kim JC. Risk factors and oncologic impact of anastomotic leakage after rectal cancer surgery. Dis Colon Rectum. 2008:51:902-8.

14. Eriksen MT, Wibe A, Norstein J, Haffner J, Wiig JN, Norwegian Rectal Cancer Group. Anastomotic leakage following routine mesorectal excision for rectal cancer in a national cohort of patients. Color Dis. 2005;7:51-7.

15. Matthiessen $P$, Hallböök $O$, Andersson M, Rutegård J, Sjödahl R. Risk factors for anastomotic leakage after anterior resection of the rectum. Color Dis. 2004;6:462-9.

16. Ito M, Sugito M, Kobayashi A, Nishizawa Y, Tsunoda Y, Saito N. Relationship between multiple numbers of stapler firings during rectal division and anastomotic leakage after laparoscopic rectal resection. Int J Color Dis. 2008; 23:703-7.

17. Kim JS, Cho SY, Min BS, Kim NK. Risk factors for anastomotic leakage after laparoscopic intracorporeal colorectal anastomosis with a double stapling technique. J Am Coll Surg. 2009;209:694-701.

18. Huh JW, Kim HR, Kim YJ. Anastomotic leakage after laparoscopic resection of rectal cancer: the impact of fibrin glue. Am J Surg. 2010;199:435-41.

19. Choi DH, Hwang JK, Ko YT, Jang HJ, Shin HK, Lee YC, et al. Risk factors for anastomotic leakage after laparoscopic rectal resection. J Korean Soc Coloproctol. 2010;26:265-73.

20. Akiyoshi T, Ueno M, Fukunaga $Y$, Nagayama S, Fujimoto $Y$, Konishi $T$, et al. Incidence of and risk factors for anastomotic leakage after laparoscopic anterior resection with intracorporeal rectal transection and double-stapling technique anastomosis for rectal cancer. Am J Surg. 2011:202:259-64.

21. Yamamoto S, Fujita S, Akasu T, Inada R, Moriya Y, Yamamoto S. Risk factors for anastomotic leakage after laparoscopic surgery for rectal cancer using a stapling technique. Surg Laparosc Endosc Percutan Tech. 2012;22:239-43.
22. Kawada K, Hasegawa S, Hida K, Hirai K, Okoshi K, Nomura A, et al. Risk factors for anastomotic leakage after laparoscopic low anterior resection with DST anastomosis. Surg Endosc. 2014;28:2988-95.

23. Katsuno H, Shiomi A, Ito M, Koide Y, Maeda K, Yatsuoka T, et al. Comparison of symptomatic anastomotic leakage following laparoscopic and open low anterior resection for rectal cancer: a propensity score matching analysis of 1014 consecutive patients. Surg Endosc. 2016;30:2848-56.

24. Kim CW, Baek SJ, Hur H, Min BS, Baik SH, Kim NK. Anastomotic leakage after low anterior resection for rectal cancer is different between minimally invasive surgery and open surgery. Ann Surg. 2016;263:130-7.

25. Leichtle SW, Mouawad NJ, Welch KB, Lampman RM, Cleary RK. Risk factors for anastomotic leakage after colectomy. Dis Colon Rectum. 2012;55:569-75.

26. Onodera T, Goseki N, Kosaki G. Prognostic nutritional index in gastrointestinal surgery of malnourished cancer patients. J Jpn Surg Soc. 1984:85:1001-5.

27. Mäkelä JT, Kiviniemi H, Laitinen S. Risk factors for anastomotic leakage after left-sided colorectal resection with rectal anastomosis. Dis Colon Rectum. 2003:46:653-60

28. Ito T, Obama K, Sato T, Matsuo K, Inoue H, Kubota K, et al. Usefulness of transanal tube placement for prevention of anastomotic leakage following laparoscopic low anterior resection. Asian J Endosc Surg. 2017;10:17-22.

29. Xiao L, Zhang WB, Jiang PC, Bu XF, Yan Q, Li H, et al. Can transanal tube placement after anterior resection for rectal carcinoma reduce anastomotic leakage rate? A single-institution prospective randomized study. World J Surg. 2011;35:1367-77.

30. Zhao WT, Hu FL, Li YY, Li HJ, Luo WM, Sun F. Use of a transanal drainage tube for prevention of anastomotic leakage and bleeding after anterior resection for rectal cancer. World J Surg. 2013;37:227-32.

31. Nishigori $H$, Ito $M$, Nishizawa $Y$, Nishizawa $Y$, Kobayashi A, Sugito $M$, Saito $N$. Effectiveness of a transanal tube for the prevention of anastomotic leakage after rectal cancer surgery. World J Surg. 2014;38:1843-51.

32. Hidaka E, Ishida F, Mukai S, Nakahara K, Takayanagi D, Maeda C, et al. Efficacy of transanal tube for prevention of anastomotic leakage following laparoscopic low anterior resection for rectal cancers: a retrospective cohort study in a single institution. Surg Endosc. 2015;29:863-7.

\section{Publisher's Note}

Springer Nature remains neutral with regard to jurisdictional claims in published maps and institutional affiliations.

Ready to submit your research? Choose BMC and benefit from:

- fast, convenient online submission

- thorough peer review by experienced researchers in your field

- rapid publication on acceptance

- support for research data, including large and complex data types

- gold Open Access which fosters wider collaboration and increased citations

- maximum visibility for your research: over $100 \mathrm{M}$ website views per year

At BMC, research is always in progress.

Learn more biomedcentral.com/submission 